\title{
ADVANCES IN ZERO ENERGY TRANSPORTATION SYSTEMS
}

\author{
O. Ahmad ${ }^{1, *}$, M. N. Ali $^{1}$, A. Chekima ${ }^{1}$
}

\begin{abstract}
Hyperloop mass transportation systems are actively developed at the moment. They represent the forefront development of the Zero Energy Transportation systems where air drag is minimized by travelling in a vacuum and friction is reduced by non-contact bearings. Hyperloop supporters are confident that the cost of their transportation systems would be low compared to existing transportation systems because of the low loss and therefore low energy consumption as well as other cost-saving techniques documented in the Hyperloop Alpha specifications. However, there are other published designs in the form of patents that may improve on the designs of the Hyperloop systems so that sustainable mass transportation systems can be realized.
\end{abstract}

Keywords: Evacuated Tube Transport, Hyperloop, Vacuum, Vacuum Tube, Zero Energy Transportation System

\section{INTRODUCTION}

Moving a large number of people and goods is vital in order to progress and survive in the coming future. Current technology in mass transportation systems consume too much energy and therefore are not sustainable in view of the global warning issues. The Paris climate change agreement proved that the majority of the world believe that global warming is a very serious issue that determines whether humans will be able to survive in future [1] [2]. Improved mass transportation systems need to be developed if we are to achieve the resolutions as agreed in this and similar climate change conventions.

The most efficient mass transportation system currently in operation is the Maglev [3] [4] [5], magnetic levitated trains. Because the train carriages are elevated from its track, the carriages are not in contact with the track. This results in virtually zero friction between the moving carriages and the tracks. At high speeds, air drag becomes more significant [6]. If we want to move faster, we need to reduce this air drag. One way of reducing air drag is to travel in a vacuum.

Vacuum tunnel mass transportation systems had been proposed in the past [7] but there was no mention of any innovative way of producing the vacuum. It was stated as being a challenging task to produce the vacuum. Other vacuum tube trains are summarised in Wikipedia as vactrains [8]. There were no clear disclosures of any innovative way of producing and managing vacuum, in these documents. However, there are inventions and related patents that may show some directions toward economical production of vacuum.

\section{EARLY INVENTIONS}

Current developments of vacuum mass transportation systems can learn from earlier inventions. They may appear to be too impractical as a whole; pieces of their technologies can be adapted to improve transportation systems that are currently being developed.

\section{Pneumatic Trains}

Pneumatic trains do not actually produce vacuum. Vacuum pumps or air compressors suck air in front of the train. Since there is vacuum in front of the train carriages, we my still consider this a method of generating vacuum. Among the latest invention in the form of a patent is the one proposed by Flynn [9] which he called Pneutrain. See Figure 1.

This paper was recommended for publication in revised form by Regional Editor Kwok-wing Chau 


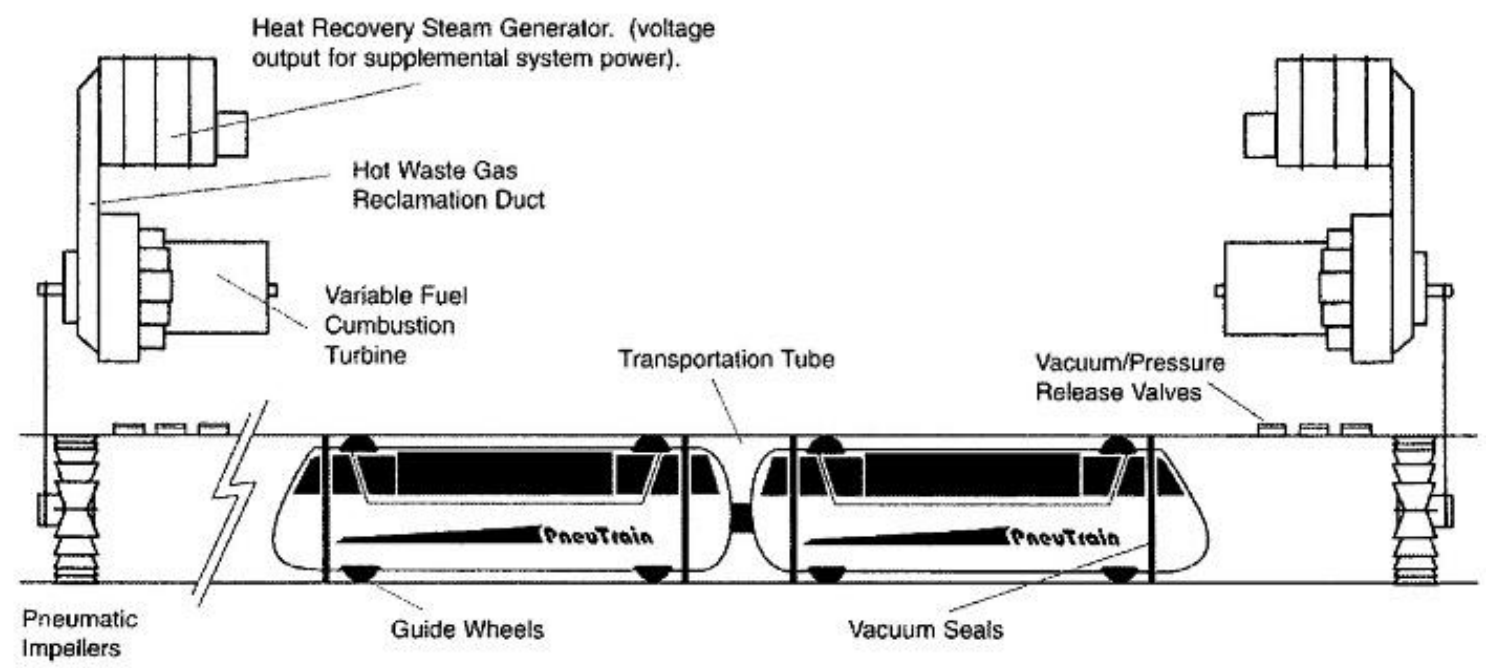

Figure 1. Pneumatic trains.

Pneumatic trains may have low air drag. However, the vacuum seals need to be tightly fitted to the walls of the tubes. Frictional losses should be high. When the seals come into contact with the walls, the seals create frictional losses that will generate heat and mass loss. Frequent replacement of the seals should be carried out in order to maintain the efficiency of the propulsion due to the vacuum pumps. These problems should limit the operating speed of the pneumatic trains compared to the pure vacuum tube trains.

\section{Gravity Trains}

Patents called "Rapid Transit System" granted in 1976 [10] and 1978 [11] and "High Speed Rapid Transit" granted in 1979 [12] use gravity as the main propulsion energy. The patent "Method and Apparatus for Global Rapid Transit" [13] may be able to utilise gravity as well. There is very little leeway in changing the acceleration of the train.

They will require downward angles in order for them to operate with a high enough acceleration. Theoretically, they will operate even when the tunnels are constructed in a straight line because of the earth's curvature but the acceleration will be very low so they are only practical for long distances as illustrated in Figure 2 .

All the other vacuum tunnel transportation systems should be able to utilise the gravity assist but they should have alternative propulsion systems to increase acceleration or for other purposes, such as moving the vehicles against an upward slope for maintenance routines.

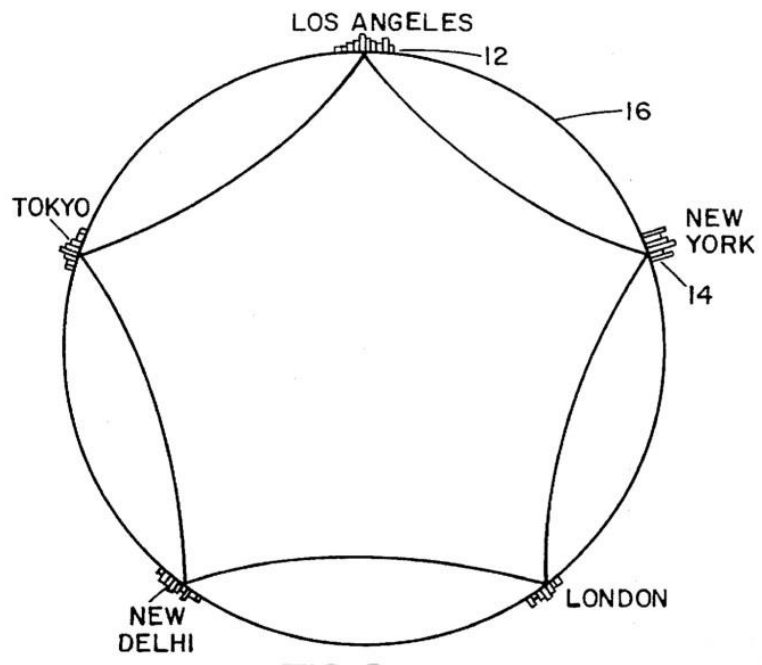

Figure 1. Routes between cities. 


\section{Geothermal Power}

The patent "Method and Apparatus for Global Rapid Transit" granted in 1996 [13] discloses a method to acquire energy and provide levitation and propulsive power by using the heat from the earth's core, as illustrated in Figure 3. This patent does not propose any vacuum in the tunnel.
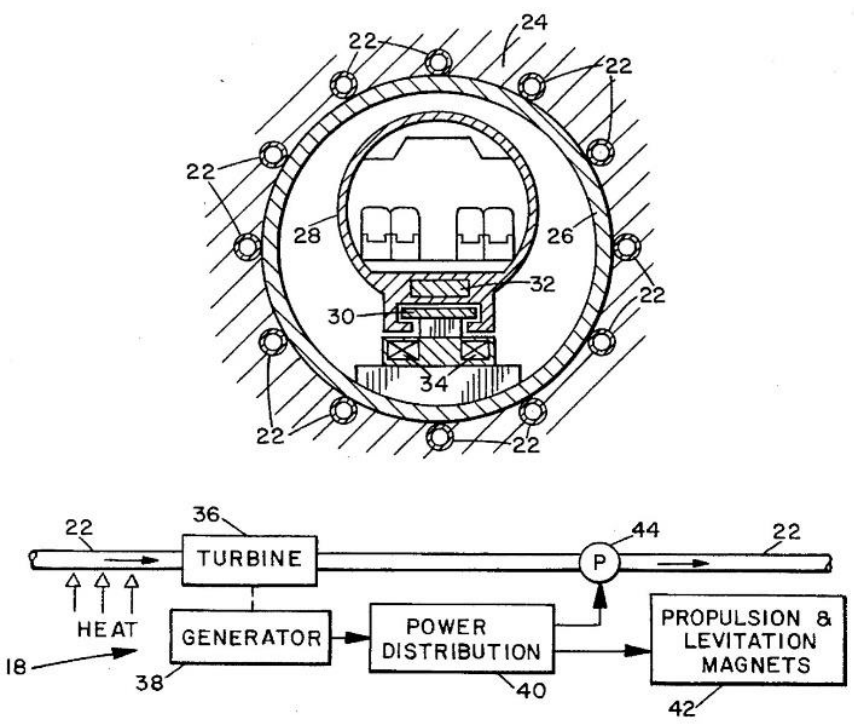

Figure 2. Geothermal power.

\section{CURRENT DEVELOPMENTS}

\section{Conventional Vacuum Tube Transportation System Patents}

Hyperloop mass transportation train configurations are the most prominent of the vacuum tube transportation systems [14]. There are other proposals and patents on vacuum tube trains. Oster proposed a patent called Evacuated Tube Transport [15]. However, it is not clear from the patent documents how the vacuum can be created. We can only assume that the vacuum would be created using the conventional means by using vacuum pumps. The Hyperloop transportation systems are not patented but are well documented in the form of specifications and business plans in the Hyperloop Alpha [14]. Hyperloop Alpha specifies that the vacuum pumps would be installed along the tubes.

\section{Zero Energy Transportation System Patent}

The Zero Energy Transportation System patent [16] attempts to propose a mass transportation system that will require zero or very small amount of energy. It utilises the zero energy travel principle whereby energy requirement can be proven to be zero when an object travels [17] in a zero loss environment. Studies on the effect of vacuum on the implementation of the zero energy travel principle are documented in Arxiv [18]. Other supporting patents were mentioned in the International Congress on Natural Sciences and Engineering (ICNSE) [19]. The Zero Energy Transportation patent proposes improvements to the other vacuum tube inventions.

\section{Vacuum Generation}

Current inventions on vacuum tube transportation such as Hyperloop Alpha and Evacuated Tube Transport do not disclose any special vacuum generation. We can assume that they use standard vacuum pumps. Zero Energy Transportation System patent proposes improvement on vacuum generation by incorporating the principle of the pneumatic train into the vacuum pumping strategies.

This patent actually just creates the vacuum economically by using the vehicles themselves as additional vacuum pumps. The vacuum pumps therefore behave like pressure release valves while the vehicles act as pistons for the vacuum pumping action, when the proper vacuum pumps cannot pump as much as the air that is pushed by the vehicles. To improve this pumping action, the vehicles should preferably be equipped with adjustable seals.

Ideally, the vacuum pumps should pump faster than the air being pushed so that they can also act as propulsive force similar to the Pneumatic propulsion systems [9]. In this way, the pumping energy is transferred to the vehicles 
as kinetic energy. The pumping energy is to be generated by electric power, as this is the only reliable means to recover energy through electrical conversions. See Figure 4.

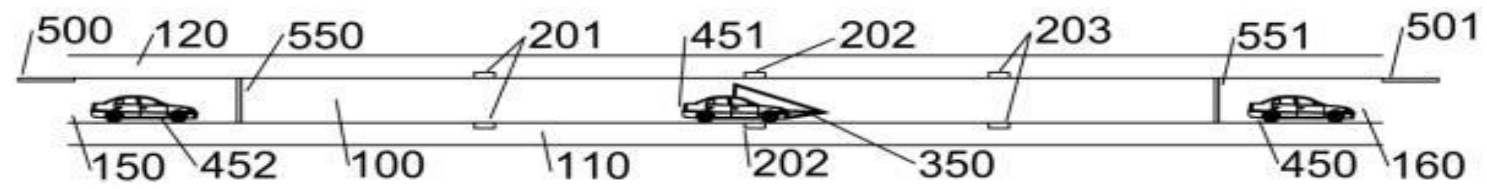

Figure 3. The zero energy transportation system patent.

These vehicles must all be equipped with electrical propulsion systems. Power can be stored in batteries inside the vehicles or outside the tunnels. They should also be equipped with an environmental system for the passengers.

The vacuum pumps also need to be opened strategically so that the vacuum pumping action aids the propulsion of the vehicles, which should be equipped with an adjustable seal, (350). These operations are best controlled by electronic computers and sensors. This is similar to pneumatic propulsions but once an acceptable level of vacuum is achieved, there is less need for the pneumatic actions. Unlike pneumatic propulsions, continuous stream of vehicles can operate at the same time.

There are many vacuum pumps scattered throughout the vacuum tunnel (100) but three are shown, vacuum pump 203 in front of the vehicle 451 inside the tunnel, just on top of the vehicle (202) and another at the back of the vehicle (201). To exploit pneumatic effect of the vacuum pumps, pump 203 should operate normally, pump 202 should operate as the release valve mode expelling shock waves as the vehicle 451 passes through and pump 201 should stop operating and fully closed. The removable seal (350) should maximise the pneumatic propulsion effect as well as the release valve mode of the vacuum pumps.

If there are too many vehicles close to each other, the vacuum pumps will operate most of the time and will probably be assisted by the shock waves of vehicles passing through. These vehicles are operating inside the vacuum tunnel (100).

The vacuum tunnel will have an entrance gate (500) entering into the embarkation chamber (150) which is sealed by the tunnel door seal (550). Vehicle 452 is therefore shown in the embarkation phase.

There is also an exit gate (501) at the disembarkation chamber (160) which is sealed by a seal door (551). Vehicle 450 is therefore at the disembarkation phase. Please note that there is no need for vacuum pumps at the embarkation chamber (150) because leaked air can be used to propel the vehicles inside the vacuum tunnel. However, vacuum pumps may be desirable at the disembarkation chamber (160).

\section{Transit Stations}

It is not clear how the embarkation and disembarkation of passengers in train carriages or capsules are carried out in Hyperloop capsules. From a picture of the doors of the capsules in Figure 5, we can assume that it would require completely sealed stations filled with air. This situation is similar for the Evacuated Tube Transport patent [15], shown in Figure 6.

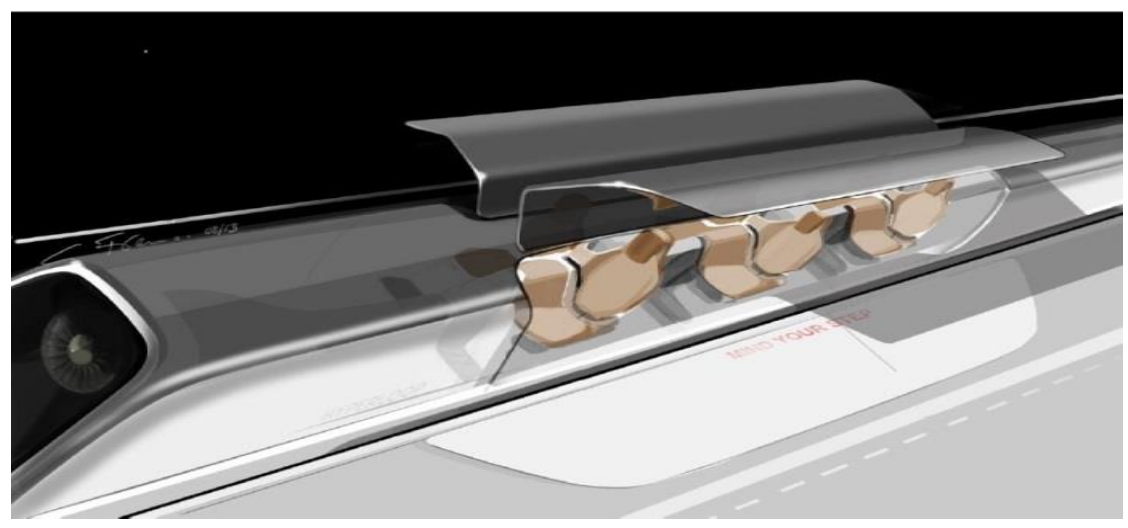

Figure 5. Hyperloop capsule doors. 
Journal of Thermal Engineering, Short Communication, Vol. 3, No. 6, Special Issue 6, pp. 1537-1543, December, 2017

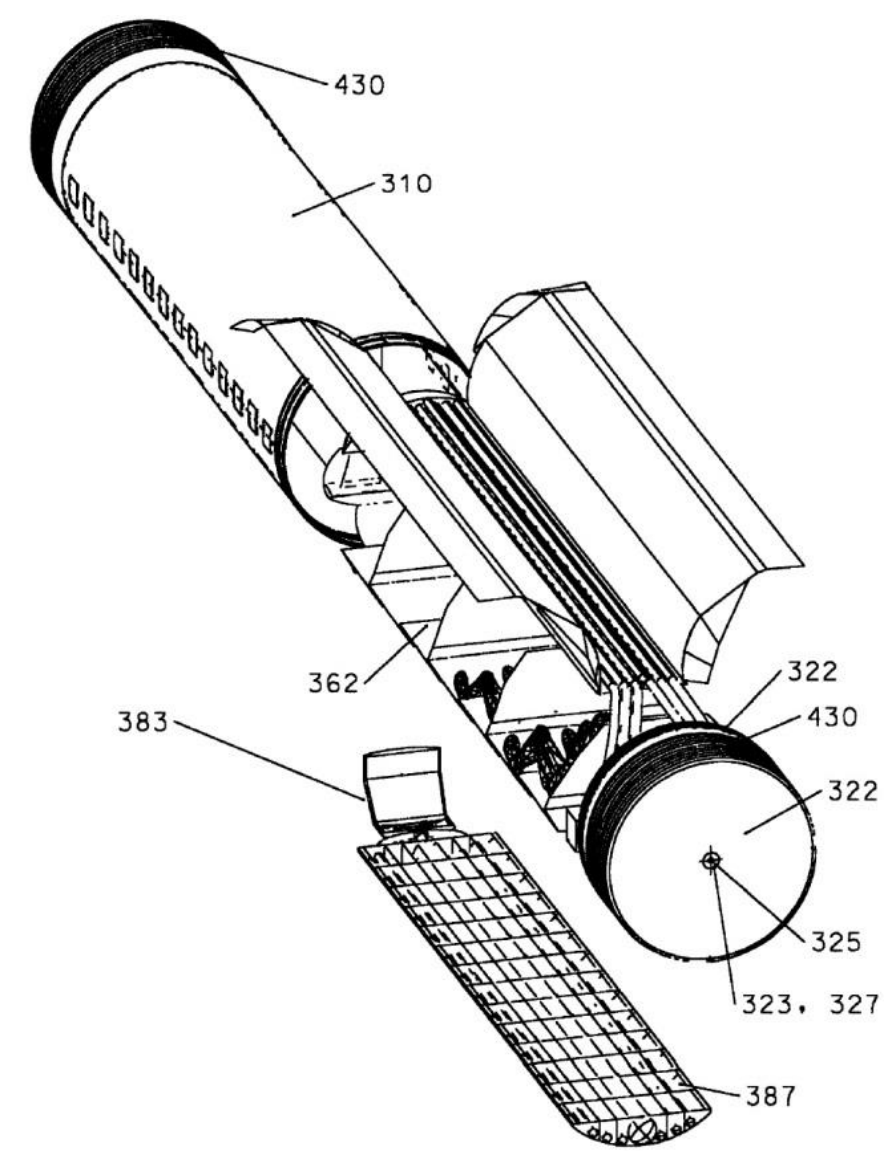

Figure 4. Evacuated tube transport's capsule doors.

Inventions are also required to control the embarkation and disembarkation of passengers in train carriages or capsules from the vacuum tubes in the most efficient way. The Zero Energy Transportation System patent proposes an alternative method. Refer to Figure 7. Embarkation and disembarkation of passengers and goods should be done at the transit chamber (170). It would require the tunnel door (101) and tunnel door seal (102) for each door of the carriage (401). To provide protection and maintenance along the vacuum tube, we may optionally install transit chamber door seal (510) at the entrance and transit chamber door seal (560) at the exit door, when the train carriage stops at a transit chamber.

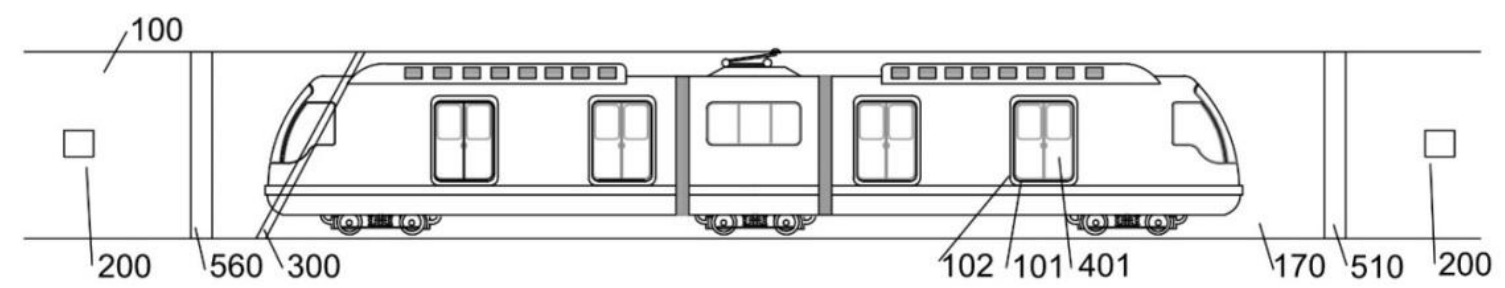

Figure 7. Zero energy transportation system's transit stations.

\section{Vacuum Generation for Filled Spaces}

Another method of creating vacuum is just by filling the spaces with the train carriages that are linked into a loop, as shown in Figure 8. The number of vacuum pumps (200) should be reduced because there is less space for air to fill. Fig. 8a shows the overall plan view; $8 \mathrm{~b}$ is a magnified plan view, while $8 \mathrm{c}$ shows the front view of the carriage (400) inside the vacuum tube (100). 


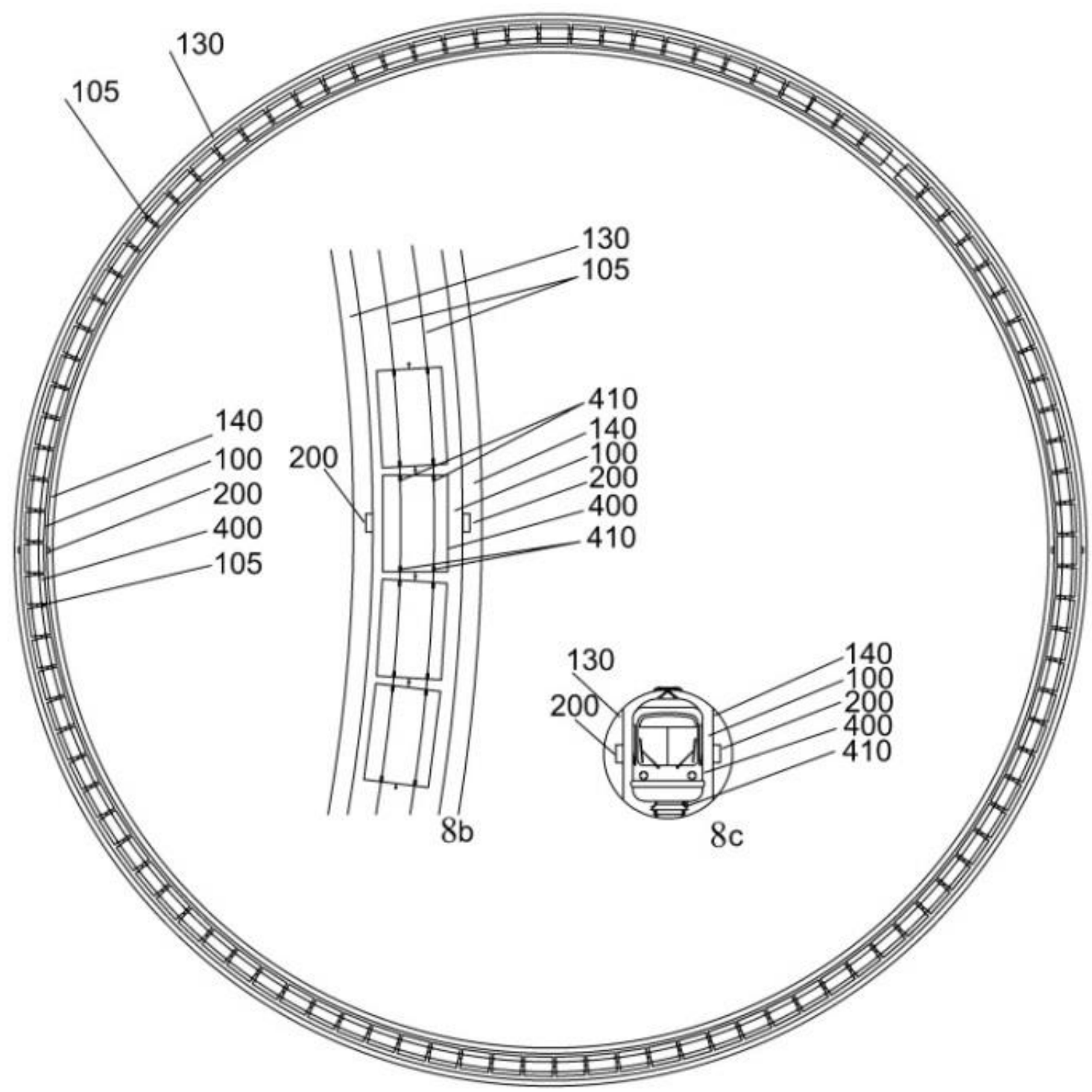

8 a

Figure 8. Vacuum by filling spaces.

\section{FUTURE DEVELOPMENTS}

There is no doubt that vacuum tube transportation in the form of the Hyperloop developments are being carried out in earnest since 2015 [20]. The most active proposal is for the San Francisco to Los Angeles route. It was also reported that Hyperloop Technologies and rival Hyperloop Transportation Technologies Inc. had held early-stage talks with governments in more than 10 countries, including China, India and the U.K., toward building a Hyperloop by 2020. However, due to the government support that is required to overcome bureaucracy, Hyperloop Technologies was also reported to say that it believes the first Hyperloop will probably be built in either the United Kingdom or from Singapore to Kuala Lumpur, Malaysia [21].

\section{REFERENCES}

[1] F. Harvey, "Paris climate change agreement: the world's greatest diplomatic success," Guardian News and

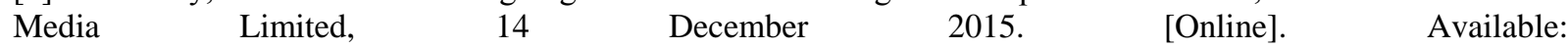
http://www.theguardian.com/environment/2015/dec/13/paris-climate-deal-cop-diplomacy-developing-unitednations. [Accessed 20 February 2016].

[2] United Nations, "Framework Convention on Climate Change," 12 December 2015. [Online]. Available: https://unfecc.int/resource/docs/2015/cop21/eng/109r01.pdf. [Accessed 20 February 2016]. 
[3] J. Powell and G. Danby, "Energy Efficiency and Economics of Maglev Transport," 20 November 2008. [Online].

Available:

http://www.aertc.org/conference/AEC_Sessions\%5CCopy\%20of\%20Session\%201\%5CTrack\%20E-

$\%$ 20Innovation\%5CIntelligent\%20Advanced\%20Transport\%5C3.\%20Dr.\%20James\%20Powell\%5CJames\%20P owell\%20presentation.pdf. [Accessed 20 February 2016].

[4] B. Mao, R. Huang and S. Jia, "Potential Applications of Maglev Railway Technology," Journal Of Transportation Systems Engineering And Information Technology, vol. 8, no. 1, p. 29-39, 1 February 2008.

[5] Shanghai Maglev Transportation Development Co., Ltd , "Chronicle of Events," Shanghai Maglev Transportation Development Co., Ltd, 2005. [Online]. Available: http://www.smtdc.com/en/gycf2.html. [Accessed 29 January 2016].

[6] M. Safoutin, "Vehicle Road Load and Fuel Economy online calculator," 3 August 2009. [Online]. Available: http://www.virtual-car.org/wheels/wheels-road-load-calculation.html. [Accessed 26 April 2011].

[7] J. Giotta, Director, Extreme Engineering: The Transatlantic tunnel. USA: Powderhouse Productions, 2003.

[8] "Vactrain," 24 November 2015. [Online]. Available: https://en.wikipedia.org/wiki/Vactrain\#cite_note-3. [Accessed 20 February 2016].

[9] P. J. Flynn, "Pneutrain Pneumatic Mass Transportation System”. U.S. Patent 2010/0083864 A1, 8 April 2010.

[10] M. A. Minovitch, "Rapid Transit System”. U.S. Patent 3,954,064, 4 May 1976.

[11] M. A. Minovitch, "Rapid Transit System". U.S. Patent 4,075,948, 28 February 1978.

[12] M. A. Minovitch, "High Speed Rapid Transit". U.S. Patent 4,148,260, 10 April 1979.

[13] G. E. Sutton, "Method and Apparatus for Global Rapid Transit". U.S. Patent 5,513,573, 7 May 1996.

[14] SpaceX, "Hyperloop Alpha," $12 \quad$ August 2013. [Online]. Available: http://www.spacex.com/sites/spacex/files/hyperloop_alpha-20130812.pdf. [Accessed 26 January 2016].

[15] D. Oster, "Evacuated Tube Transport”. U.S. Patent 5,950,543, 14 September 1999.

[16] O. Ahmad, "Zero Energy Transportation System”. WIPO Patent PCT/IB2013/053428, 1 May 2013.

[17] O. Ahmad, A. Kiring and A. Chekima, "Optimum Low Friction Energy Saving Car," Engineering eTransaction, vol. 6, no. 2, 2011.

[18] O. Ahmad, A. Kiring and A. Chekima, "Zero Energy Travel," 11 September 2011. [Online]. Available: http://arxiv.org/abs/1109.3764. [Accessed 20 February 2016].

[19] O. Ahmad, A. Kiring and A. Chekima, "Zero Energy Transportaion Systems," in International Congress on Natural Sciences and Engineering (ICNSE), Kyoto, 2014.

[20] J. Nicas, "Hyperloop Race Picks Up Speed," WSJ, 21 January 2016. [Online]. Available: http://www.wsj.com/articles/hyperloop-race-picks-up-speed-1453426042. [Accessed 29 January 2016].

[21] M. Grothaus, "Two Companies Are Racing To Build The First Hyperloop," Fast Company, 22 January 2016. [Online]. Available: http://www.fastcompany.com/3055801/fast-feed/two-companies-are-racing-to-build-thefirst-hyperloop. [Accessed 23 February 2016]. 